\title{
The Investigation of the Influence of Modern Coating Applied to the Cutting Inserts During Machining
}

\begin{abstract}
Ales Jaros ${ }^{1}$, Josef Sedlak ${ }^{1}$, Petr Jasek ${ }^{1}$, Jozef Majerik ${ }^{2}$, Igor Barenyi ${ }^{2}$, Jan Bezecny ${ }^{2}$,
${ }^{1}$ Department of Machining Technology, Institute of Manufacturing Technology, Faculty of Mechanical Engineering, Brno University of Technology, Technicka 2896/2, Brno 616 69, Czech Republic. E-mail: jaros.a@fme.vutbr.cz, sedlak@fme.vutbr.cz, y137357@stud.fme.vutbr.cz

${ }^{2}$ Faculty of Special Technology, Alexander Dubcek University of Trencin, Pri Parku 19, Trencin 911 06, Slovakia. Email: jozef.majerik@tnuni.sk, igor.barenyi@tnuni.sk, jan.bezecny@tnuni.sk
\end{abstract}

This article deals with benefits of PVD and CVD coatings applied to cutting inserts during face milling technology. The coatings deposited on applied cutting inserts were used to extension the tool life. Machining process was carried out on the conventional vertical milling machine tool. This machining process was performed without coolant. The set up of cutting conditions were constant throughout the machining and low-alloy Cr-Mo steel DIN $42 \mathrm{CrMoS4}$ (W. Nr. 1.7227) was used as workpiece material in the realized process of experiments. The aim of this investigation was to compare coated and uncoated changeable cutting inserts clamped in the milling cutter and find out the benefits of PVD or CVD coatings during realization of face milling process. The monitored parameters were the force load measured by piezoeletrical dynamometer Kistler 9257B and the obtained flank wear measured by optical microscope.

Keywords: Face milling, cutting inserts, coatings, force loading, flank wear, tool life.

\section{Introduction}

The most widely used materials for production of cutting inserts are cemented carbides which are deposited by PVD or CVD coating method [1]. Chemical composition, heat treatment, microstructure, surface morphology [13] and, at present, the most significant very hard coatings have the greatest influence on their mechanical properties [2]. It is generally known that coatings increase mechanical properties, for example hardness, wear resistance, maximal application temperature and thus they extend the tool life [3], [14]. There are two basic methods for production coatings on cutting tools - Physical vapour deposition (PVD) and Chemical vapour deposition (CVD). PVD is working in lower temperatures (450-600) ${ }^{\circ} \mathrm{C}$ than CVD (1000-1200) ${ }^{\circ} \mathrm{C}$. Both technologies can be used for deposition coating to the cutting insert made by cemented carbides [4], [5]. PVD coatings are more often used for milling applications because the inserts are subjected to greater shocks as they still come in and out of the cut interrupted cut. The PVD coating was synthesized by cathodic arc evaporation and CVD coating are formed as the result of reactions between various gaseous phases and the heated surface of substrates within the CVD reactor [4], [6]. Coatings can be deposited as a mono-layer and in this modern time as a multi-layer or nano-layer [7]. Dry machining is very typical application for milling; it is one of the major trends in modern manufacturing. High performance dry machining generates severe cutting conditions associated with high temperature and stress within cutting zone [8]. Coatings based on $\mathrm{Al}$, for example (Ti,Al)N and nanocomposite $(\mathrm{Ti}, \mathrm{Al}, \mathrm{Si}) \mathrm{N}$ are recommended for dry milling, because they can withstand temperatures up to $900^{\circ} \mathrm{C}$ [9].

\section{Experimental procedure}

The main goal of this experiment was to find out the benefits of PVD and CVD coatings deposited on cutting inserts during face milling of low-alloy steel DIN $42 \mathrm{CrMoS} 4$ (W. Nr. 1.7227). Monitored parameters were the force load and flank wear. Dynamometer Kistler 9257B was used to measure force loading and optical microscope to measure flank wear.

\subsection{Cutting tools}

Four types of cutting inserts ADMX 160608SR-M were chosen for this experiment. One of them was uncoated; two types were deposited by PVD coatings (nanolayers coatings) and one by CVD coating (multi-layer coating). The marking of cutting tools and parameters of used coatings are described in Tab. 2. The thickness of deposited coating was measured by calotest. Details of tested cutting tools are shown in. Fig. 2.
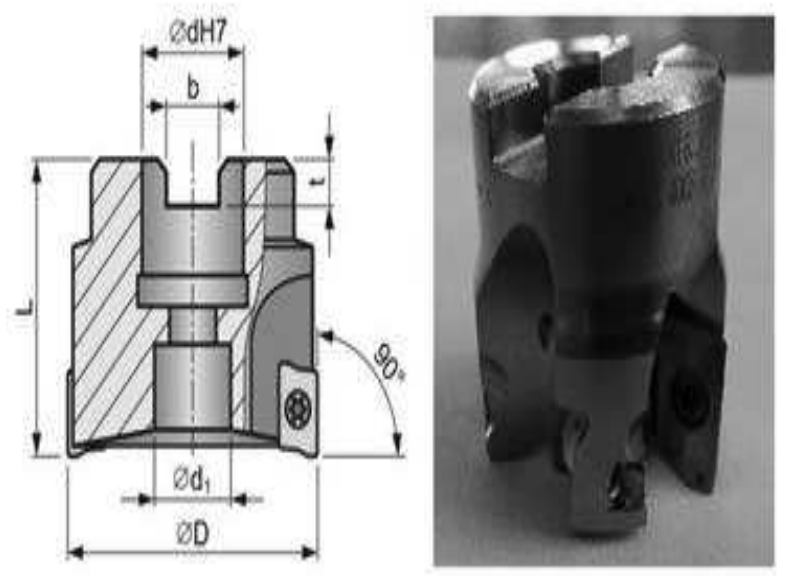

Fig. 1 Used face milling cutter 40A04R-S90AD16E-C [10] 
Tab. 1 Characteristic of used milling cutter [11]

\begin{tabular}{|c|c|c|c|c|c|c|}
\hline $\mathrm{D}[\mathrm{mm}]$ & $\mathrm{dH} 7[\mathrm{~mm}]$ & $\mathrm{d}_{1}[\mathrm{~mm}]$ & $\mathrm{L}[\mathrm{mm}]$ & $\mathrm{B}[\mathrm{mm}]$ & $\mathrm{T}[\mathrm{mm}]$ & $\mathrm{Z}[-]$ \\
\hline 40 & 16 & 14 & 40 & 8.4 & 5.6 & $1-4$ \\
\hline
\end{tabular}

Tab. 2 Marking of tested cutting inserts

\begin{tabular}{|c|c|c|c|c|}
\hline Cutting tool & Coating technology & Type of coating & Structure & Thickness of coating \\
\hline A & uncoated & - & - & - \\
\hline B & CVD & TiN + TiCN $+\mathrm{Al}_{2} \mathrm{O}_{3}$ & multi-layer & $7.0 \mu \mathrm{m}$ \\
\hline C & PVD & TiN + TiAlN & nano-layer & $3.2 \mu \mathrm{m}$ \\
\hline D & PVD & TiN + TiAlN + TiAlSiN & nano-layer & $3.6 \mu \mathrm{m}$ \\
\hline
\end{tabular}

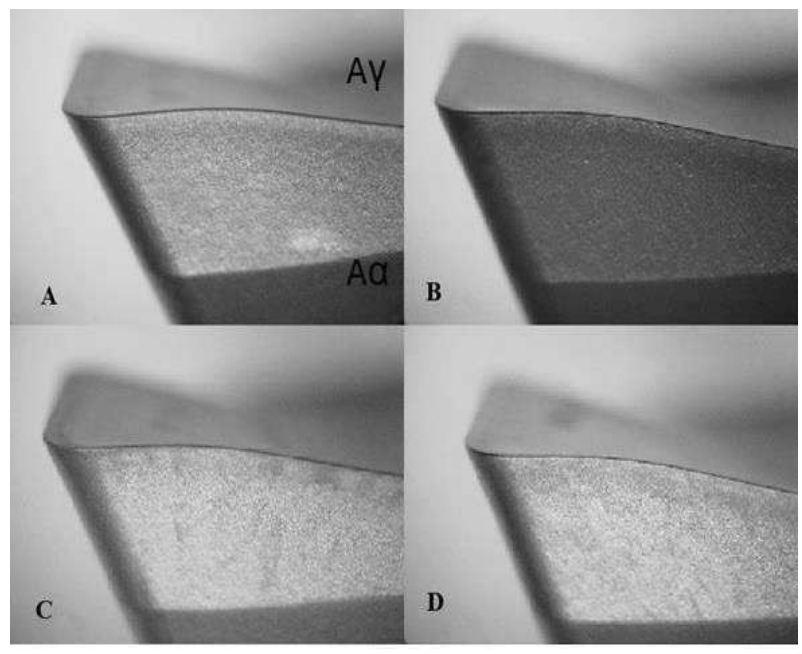

Fig. 2 Details of tested cutting inserts in mode of light microscopy before cutting tests.

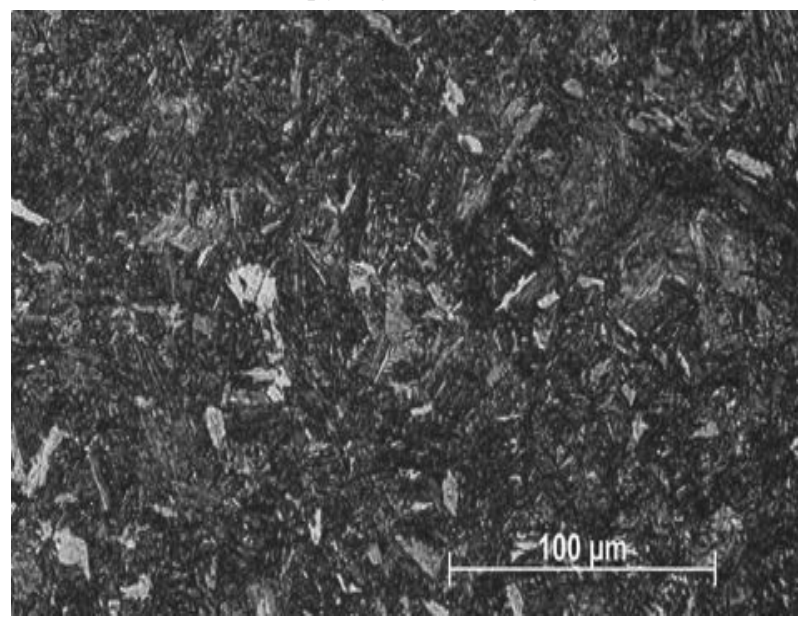

Fig. 3 Microstructure of steel 42CrMoS4.Etched in nital (500x)

\subsection{Workpiece material}

Workpiece material of type $42 \mathrm{CrMoS} 4$ has the Slovak equivalent with the designation STN 41 5142. This is low alloyed, stainless, chromium - molybdenum steel for the quenching and tempering. After hardening process application usually reaches hardness approximately of 58 HRC. It is possible to reach the hardness up to $1000 \mathrm{MPa}$ with the $100 \mathrm{~mm}$ components by the sufficient toughness. It is usually hardening into the less resolute medium, because it is susceptible to occurrence of hardening cracks in the notch areas or in surface defects. In the hardened state has very good wear resistance and belongs to the most often using steels for the quenching and tempering. Low-alloy Cr-Mo construction steel (W. Nr. 1.7227) was used as workpiece material. This steel is often used for highly stressed machine parts, such as parts of boilers or steam turbines. Dimensions of the workpiece (pre-machined) were $150 \times 10 \times 30 \mathrm{~mm}$. Chemical composition is shown in Tab. 3. Fundamental mechanical properties of this steel can be seen in Tab. 4.

It is the steel with higher hardenability and this steel is usually used for the high-stressed machine parts, automobiles, gear wheels, compressor drive wheels and shafts. Material 42CrMo4 has limited weldability. Therefore it is recommended to preheat the material to 200-300 ${ }^{\circ} \mathrm{C}$ while the upper limit should not be exceeded. As a quenching medium, it is recommended synthetic polymers and oils with regard to the quenching crack. To achieve the uniform values after quenching and tempering of larger diameters (mostly with the forged) contribute normalization annealing as operation unlike the quenching and tempering. I tis machined in the soft annealing state at lower strength also with the quenching and tempering state. It can be seen the recommended temperatures for each types of heat treatment in Tab. 5 .

Tab. 3 Chemical composition of Cr-Mo steel 42CrMoS4

\begin{tabular}{|c|c|c|c|c|c|c|c|}
\hline Chemical composition & $\mathrm{C}[\%]$ & $\mathrm{Si}[\%]$ & $\mathrm{Mn}[\%]$ & $\mathrm{P}[\%]$ & $\mathrm{S}[\%]$ & $\mathrm{Cr}[\%]$ & $\mathrm{Mo}[\%]$ \\
\hline Min. & 0.38 & - & 0.60 & - & 0.020 & 0.90 & 0.15 \\
\hline Max. & 0.45 & 0.40 & 0.90 & 0.025 & 0.035 & 1.20 & 0.30 \\
\hline
\end{tabular}

Tab. 4 Fundamental mechanical properties of steel $42 \mathrm{CrMoS} 4$

\begin{tabular}{|c|c|c|c|}
\hline Diameter $d[\mathrm{~mm}]$ & $\mathrm{d}<16$ & $16<\mathrm{d}<40$ & $40<\mathrm{d}<100$ \\
\hline Width $t[\mathrm{~mm}]$ & $\mathrm{t}<8$ & $8<\mathrm{t}<20$ & $20<\mathrm{t}<60$ \\
\hline $\operatorname{Re}_{\min .}[\mathrm{MPa}]$ & 900 & 750 & 650 \\
\hline$R_{m}[\mathrm{MPa}]$ & $1100-1300$ & $1000-1200$ & $900-1100$ \\
\hline$A_{\min }[\%]$ & 10 & 11 & 50 \\
\hline$Z_{\min .}[\%]$ & 40 & 45 & 35 \\
\hline$K V_{\min }[\mathrm{J}]$ & 30 & 35 & 50 \\
\hline
\end{tabular}


Tab. 5 Recommended temperatures of heat treatment of steel42CrMoS4

\begin{tabular}{|c|c|c|c|c|}
\hline $\begin{array}{c}\text { Normalization } \\
\text { annealing }\left[{ }^{\circ} \mathrm{C}\right]\end{array}$ & $\begin{array}{c}\text { Soft annealing } \\
{\left[{ }^{\circ} \mathrm{C}\right]}\end{array}$ & $\begin{array}{c}\text { Isothermal } \\
\text { annealing }\left[{ }^{\circ} \mathrm{C}\right]\end{array}$ & $\begin{array}{c}\text { Hardening tempera- } \\
\text { ture }\left[{ }^{\circ} \mathrm{C}\right]\end{array}$ & $\begin{array}{c}\text { Tempering tempera- } \\
\text { ture }\left[{ }^{\circ} \mathrm{C}\right]\end{array}$ \\
\hline $550-880$ & $680-720$ & $800-900$ & $820-860$ & $540-680$ \\
\hline
\end{tabular}

The dependence of mechanical values on the tempering temperatures of material $42 \mathrm{CrMoS} 4$ can be seen in Fig. 3 and tempering curve of material $42 \mathrm{CrMoS} 4$ in Fig. 4. In the thermal range from 200 to $400{ }^{\circ} \mathrm{C}$ it usually becomes to the significant decreasing of toughness. This interval of temperatures corresponds to the development area of temper brittleness. Microstructure of test specimen (can be seen in Fig. 5) is homogeneous and is formed with the high-tempered martensite and fine evenly distributed secondary carbides. It corresponds to the quenched-tempered condition.

\subsection{Quasistatic nanoindentation}

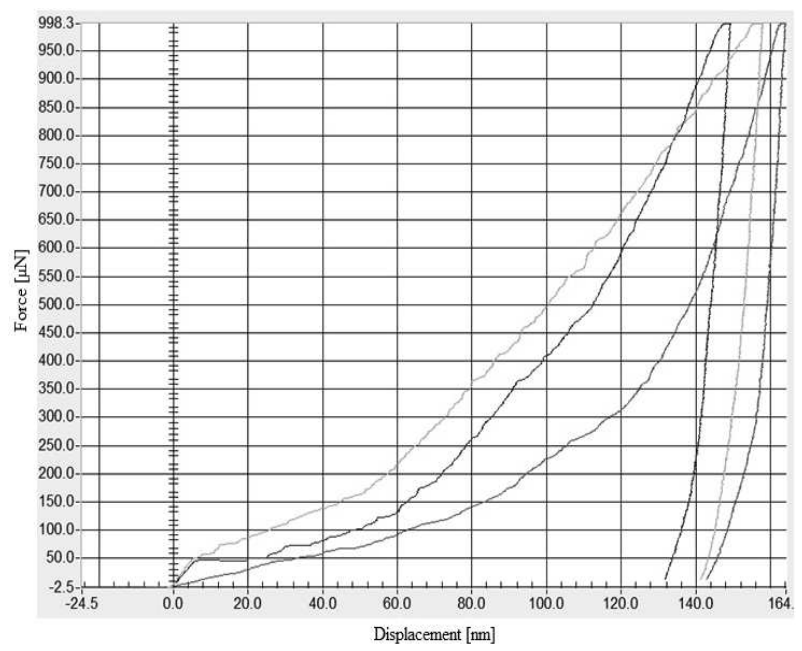

Fig. 4 Nanoindentation load-displacement curves for steel $42 \mathrm{CrMoS} 4$

Quasistatic nanoindentation measurements have been realized in order to study mechanical properties of $42 \mathrm{CrMoS} 4$ steel. Nanohardness and Young modulus were measured by the nanoindentation measuring device Hysitron TI 950 Triboindenter (directly from the company Bruker Ltd.) in the CEDITEK Laboratory of Mechanical testing in Trencin (Faculty of special technology). In this part of realized investigations, a number of tests were realized by the nanoindentation techniques. All realized nanoindentation tests were performed in the room temperature with the application of Berkovich indenter. Realized investigations have the capability to measure the Young modulus and also hardness at the small volumes. During all realized quasistatic nanoindenation tests, the load together with the displacement were recorded while Berkovich indenter was pressed onto the measuring specimen surface with the standard loading and unloading profiles. Measured results can be seen in Fig. 4 as the load- displacement curves for steel $42 \mathrm{CrMoS} 4$. The young modulus $\mathrm{Er}$ was gained with the initial unloading stiffness $S$. The stiffness contact is then associated to the reduced Young modulus Er according to the equation (1):

$$
E_{r}=\frac{\sqrt{\pi}}{2 . \beta} \cdot \frac{S}{A_{c}}[\mathrm{GPa}]
$$

Where $B$ is the constant which depend on geometry of used Berkovich indenter. $A_{c}$ is the contact area of indentation. Averaged measured value of Young modulus for steel $42 \mathrm{CrMoS} 4$ was $E_{r}=160.7 \mathrm{GPa}$. Averaged measured value of hardness for the same testing material was $H=$ $2.13 \mathrm{GPa}$.

\subsection{Cutting conditions}

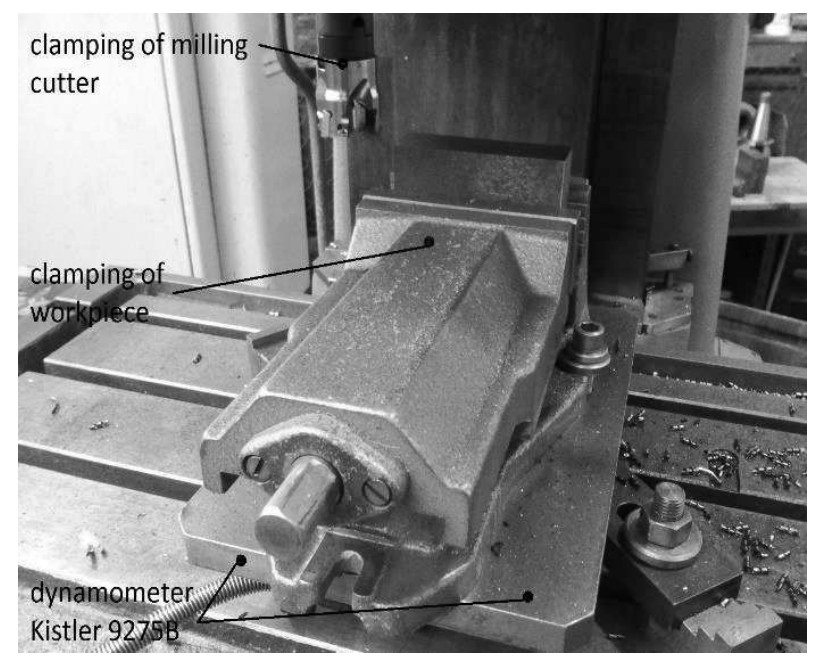

Fig. 5 The experimental procedure of clamping milling cutter and workpiece material

Tab. 6 Cutting conditions for the experimental milling

\begin{tabular}{|c|c|c|}
\hline Cutting condition & variable & value \\
\hline Cutting speed & $v_{c}\left[\mathrm{~m} \cdot \mathrm{min}^{-1}\right]$ & 176 \\
\hline Feed rate speed & $v_{f}\left[\mathrm{~mm} \cdot \mathrm{min}^{-1}\right]$ & 250 \\
\hline Feed rate per tooth & $f_{z}\left[\mathrm{~mm} \cdot \mathrm{mooth}^{-1}\right]$ & 0.179 \\
\hline Radial depth of cut & $a_{p}[\mathrm{~mm}]$ & 3 \\
\hline Axial width of cut & $a_{e}[\mathrm{~mm}]$ & 30 \\
\hline
\end{tabular}

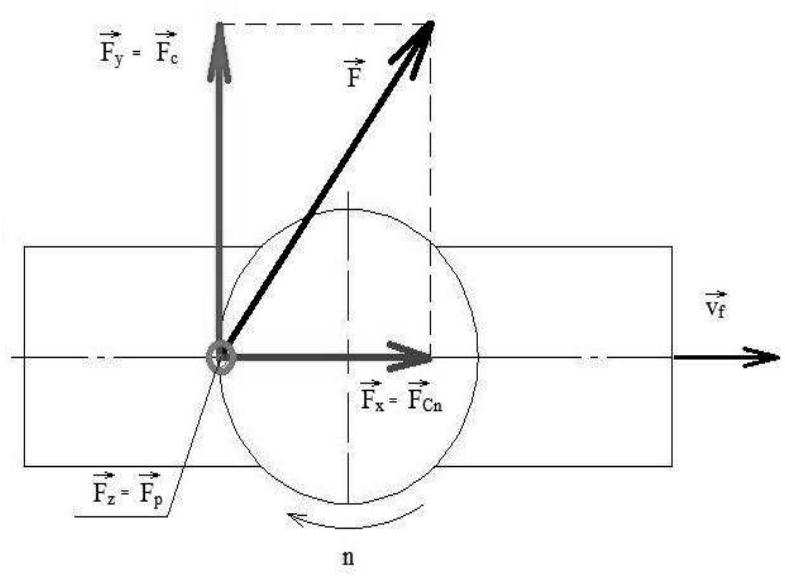

Fig. 6 Distribution of force loading [12] 
The face milling process was carried out on conventional three-axis vertical milling machine tool FB 32V without using process liquid, so it was dry machining. Set up cutting conditions were constant during performed machining process. The clamping of the workpiece and milling cutter are shown in Fig. 5 and set up cutting conditions can be seen in Tab. 6 .

The primary monitored parameter was force load generated by milling cutter. Force load was measured in three axes by the piezoelectric dynamometer Kistler 9257B equipped with eight-channel amplifier 5070A. Dynoware software was used for acquired data processing (can be seen in Fig. 7). The dynamometer senses reactions induced by cutting tool while removing chip during milling process in the Cartesian coordinate system $(F x, F y, F z)$ which can be transformed to machining coordinate system $\left(F c, F c_{N}, F p\right)$, depending on the cutter angle [12]. The sampling frequency was set up to $1600 \mathrm{~Hz}$, measuring time was 40 seconds. Basic distribution of force loading is shown in Fig. 6. The secondary monitored parameter was flank wear measured by optical microscope - criterion $V B$ was used. The experimental procedures were considered to completed if the value of the criterion $V B$ reached a value of $V B=0.2 \mathrm{~mm}$.

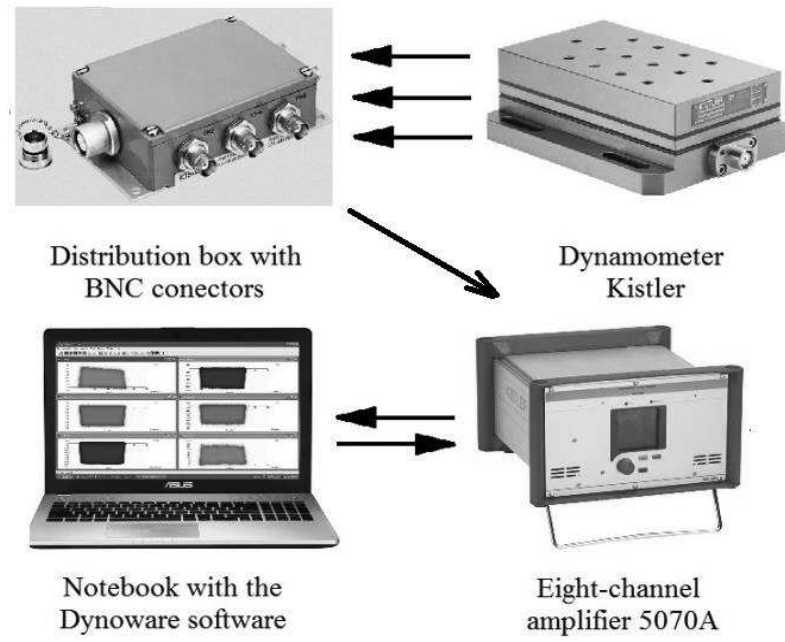

Fig. 7 The Kistler data acquisition and processing [11]

\section{Results and discussion}

Uncoated cutting inserts were tested first and then all coated. Each tested cutting inserts reached set up maximum value of flank wear criterion $V B=0.2 \mathrm{~mm}$ with a different number of passes, the different tool life has been achieved. One pass represents machining time $t=22.8 \mathrm{~s}$.

\subsection{Force loading}

The monitored parameters were the values of cutting forces during machining. The time series of force load for all tested cutting tools are shown in Fig. 8-11; different tool life has been achieved. The best result was achieved with cutting tool $\mathrm{D}$ and with this tool was carried out the most passes (110) then was achieved the limit value of criterion $V B$, the worst result with uncoated cutting inserts (tool A), the limit $V B$ was achieved only after three passes. These results were predicted, because coatings ex- tend the tool life and reduce the cutting forces during machining. It is commonly known, that force load during machining is growing up due to the increasing wear. The lowest value of increase of cutting force can be observed with tool $\mathrm{D}$, in this case the machining process was the most stable. The y-axis (can be seen in Fig. 8 - 11) does not correspond to the real machining time. Real machining time is then shown in Tab. 7 for all tested tools (when the tool reached criterion $V B=0.2 \mathrm{~mm}$ ). The values of cutting force in a particular point in time for all tested milling cutters can be seen in Fig. 12. The continuous increase of cutting forces can be observed for all tested milling cutters.

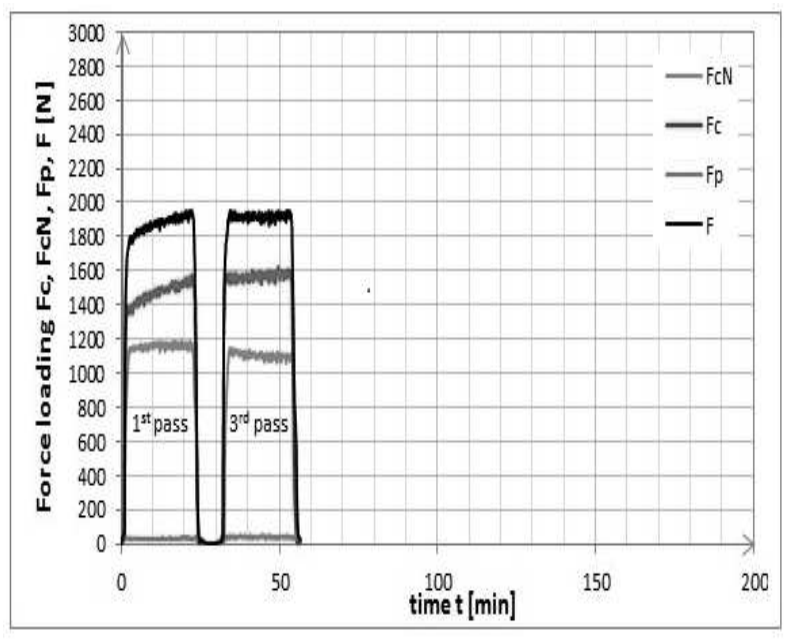

Fig. 8 Time series of the force loading for cutting tool A (uncoated)

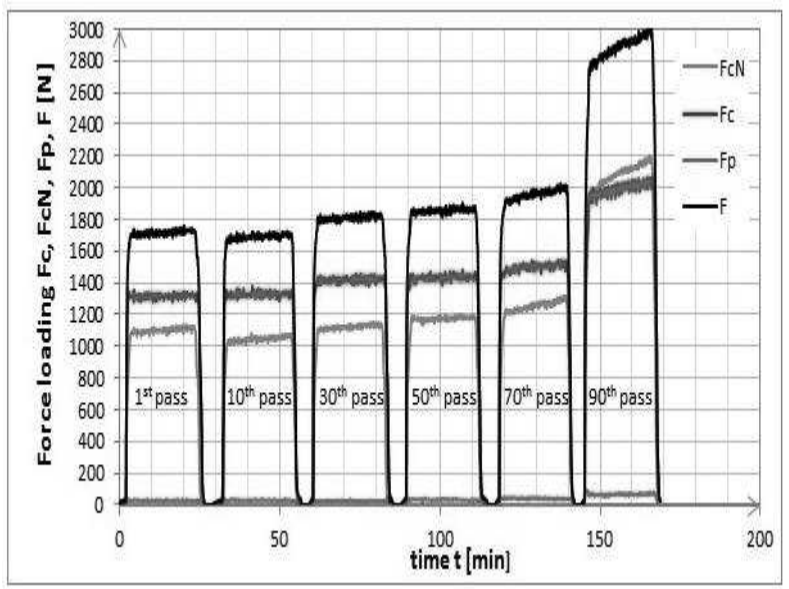

Fig. 9 Time series of the force loading for cutting tool $B$ (with $\mathrm{CVD}$ coating $\mathrm{TiN}+\mathrm{TiCN}+\mathrm{Al}_{2} \mathrm{O}_{3}$ )

Regression equations are shown for immediate detection of cutting force at a given time. The best result - lowest value of mean cutting force $F c$ was reached with tool $\mathrm{D}$ in which the best tool life was achieved. The highest values of $F c$ are not marked (for cutting tool B and D see Fig. 12) because in these cases, a large part of the edges was broken, and can be seen in Fig. 15a-d. Here the value of flank wear $V B$ has changed sharply from 0.19 $\mathrm{mm}$ (80th pass) to $0.65 \mathrm{~mm}$ (90th pass) for cutting inserts $\mathrm{B}$ and from $0.15 \mathrm{~mm}$ (100th pass) to $1.4 \mathrm{~mm}$ (110th pass) for cutting tool D. 


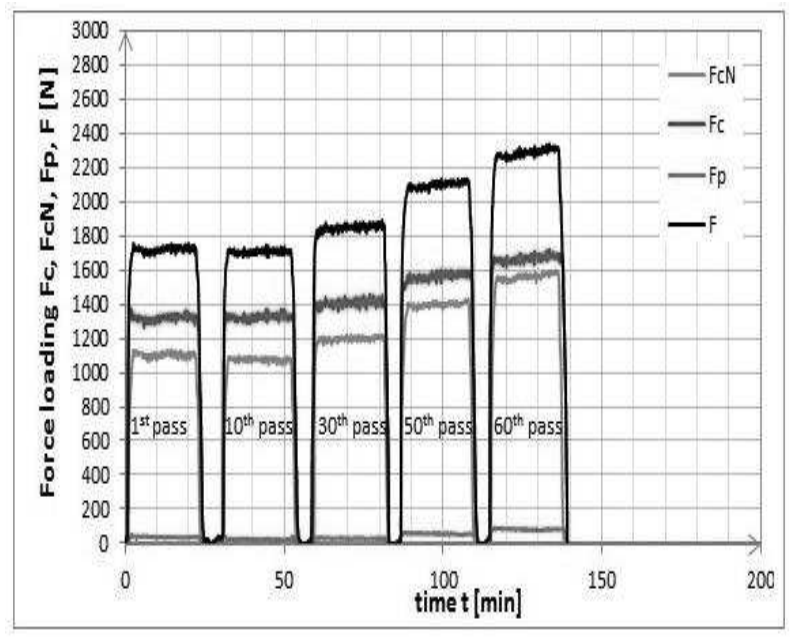

Fig. 10 Time series of the force loading for cutting tool $C$ (with PVD coating TiN + TiAlN)

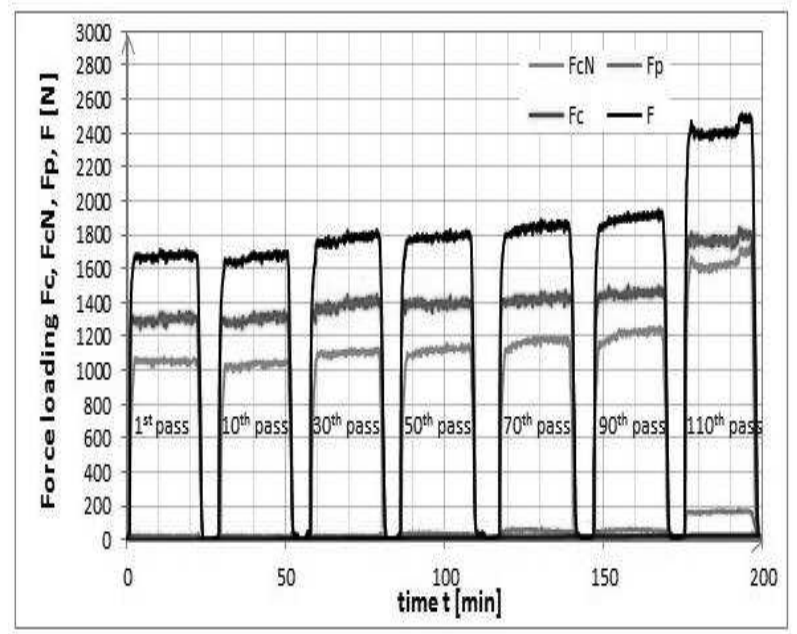

Fig. 11 Time series of the force loading for cutting tool $D$ (with PVD coating TiN + TiAlN + TiAlSiN)

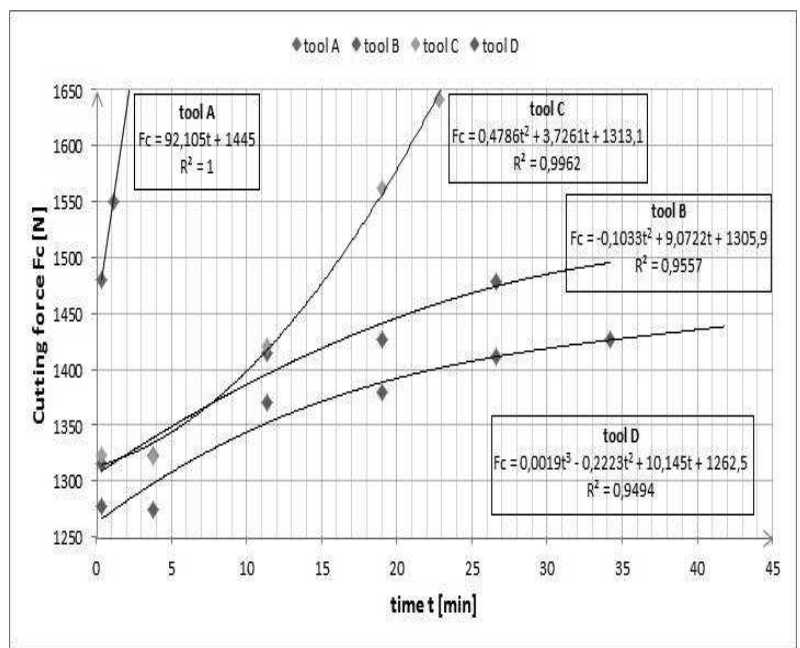

Fig. 12 The values of cutting force Fc for all tested tools in particular point in time

Tab. 7 Real machining time for all tested cutting milling cutters

\begin{tabular}{|c|c|c|c|c|}
\hline Cutting tool & $\mathrm{A}$ & $\mathrm{B}$ & $\mathrm{C}$ & $\mathrm{D}$ \\
\hline Machining & 1.14 & 34.2 & 22.8 & 41.8 \\
time & min & min & min & min \\
\hline
\end{tabular}

\subsection{Flank wear $V B$ after machining}

The values of flank wear were measured by optical microscope and flank wear was measured for each 10th pass. The maximum value of flank wear $V B$ was set up to $V B=0.2 \mathrm{~mm}$ and was reached by all tested cutting inserts. Comparison of flank wear for all tested cutting tools can be seen in Fig. 13a, b.. As expected, uncoated cutting tool A reached maximum value of flank wear $V B$ as the first (only after the 3rd cut) Several times more passes (cuts) were carried out with all coated cutting inserts (cutting tools B, C and D). The best result was achieved with cutting tool D (which can be seen in Fig. 14). The wear mechanism was analysed with optical (seen in Fig. 13a,b) and Tescan Vega scanning electron microscopy SEM (can be seen in Fig. 15a-d). Predominantly abrasive wear with different intensity can be observed on all tested milling cutters (the highest on uncoated cutting tool A) with participation of other wear mechanisms (adhesive, plastic deformation, fragile fracture). Adhering cutting chip can be observed on face on uncoated cutting insert A. It is obvious that all tested cutting tools are particularly worn, but the coated cutting inserts could work at higher cutting and feed rate speeds in comparison with uncoated tool A.

\section{Conclusions}

Based on the force loading, flank and face wear of the experimental face milling low-alloy $\mathrm{Cr}$-Mo construction steel DIN 42CrMoS4 the following conclusions for the uncoated and coated cutting inserts can be made:

- all tested cutting inserts reached the maximum value of criterion $V B=0.2 \mathrm{~mm}$

- $\quad$ set up cutting conditions were constant for all tested cutting inserts during experimental machining,

- $\quad$ only 3 passes were made with uncoated tool A when the maximum value of criterion $V B$ was reached - worst result,

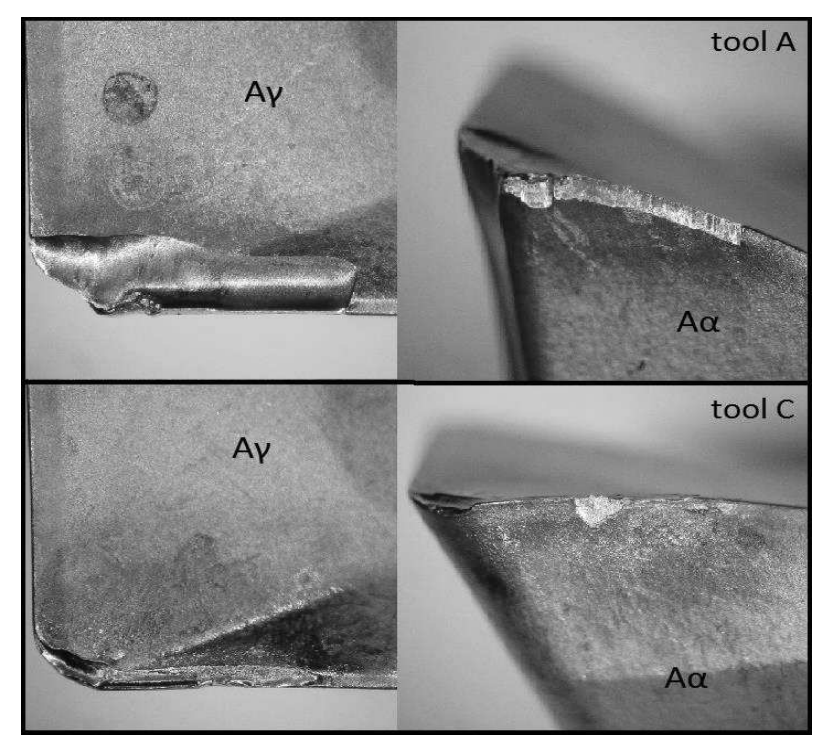

Fig. 13a Face $(A \gamma)$ and flank $(A \alpha)$ wear of all tested cutting inserts (optical microscopy) 


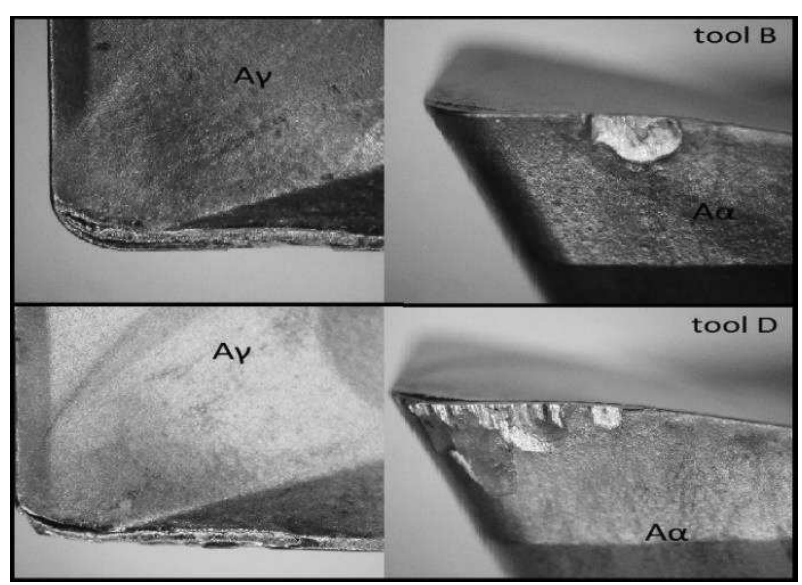

Fig. 13b Face $(A \gamma)$ and flank $(A \alpha)$ wear of all tested cutting inserts (optical microscopy)

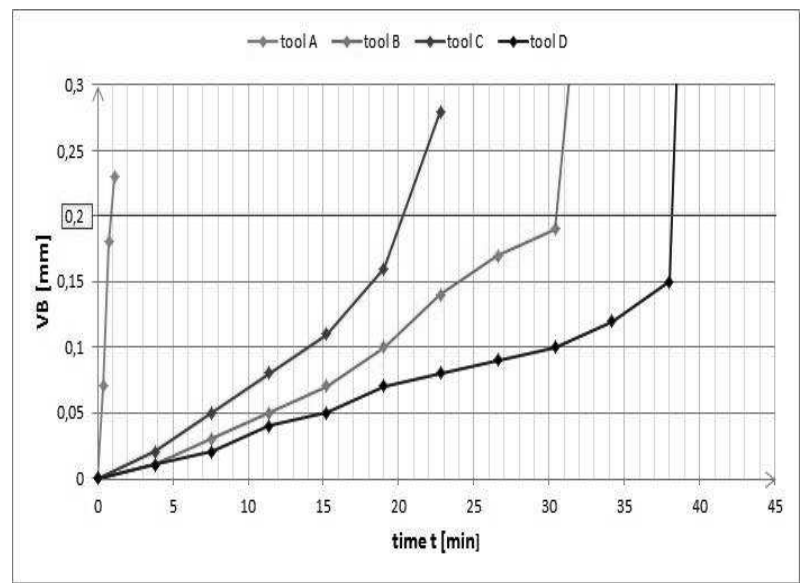

Fig. 14 Comparison of flank wear (criterion VB) for all tested cutting inserts

- 110 passes were carried out with cutting insert with nano-layer PVD coating ( $\mathrm{Ti}) \mathrm{N}+(\mathrm{Ti}, \mathrm{Al}) \mathrm{N}$ $+(\mathrm{Ti}, \mathrm{Al}, \mathrm{Si}) \mathrm{N}$ - best result (cutting tool $\mathrm{D})$,

- the best tool life was achieved with cutting insert $\mathrm{D}$, which represents machining time $t=41.8$ $\min$,

- the uncoated cutting insert reached the limit flank wear $V B=0.2 \mathrm{~mm}$ for 3 passes, the other coated cutting inserts reached negligible increase of flank wear (for the same machining time),

- the best wear resistance in terms of lowest increase of cutting force and face and flank wear during testing was achieved with tool $\mathrm{D}$,

- almost twice tool life was achieved with cutting insert $\mathrm{D}$ in comparison of tool $\mathrm{C}$ (both are coated, but with different PVD coating),

- partial flank and face wear was observed on all tested milling cutters,

- on the flank wear had the greatest influence abrasive mechanism and plastic deformation,

- face milling was more stable when cutting tool
D was used, non-stable with uncoated cutting tool A,

- $\quad$ PVD and CVD coatings reduce the force load and thereby reduce the flank wear and extend the tool life,

- uncoated cutting insert is not recommended for this type of application,

- coated cutting inserts (tools B, C, D) could work at higher cutting and feed rate speeds.

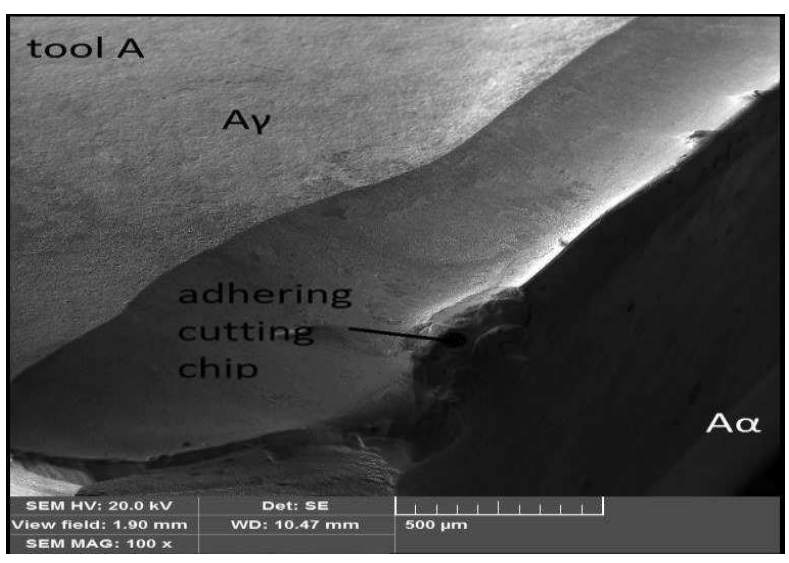

Fig. 15a Flank and face wear of all tested tools A (scanning electron microscopy)

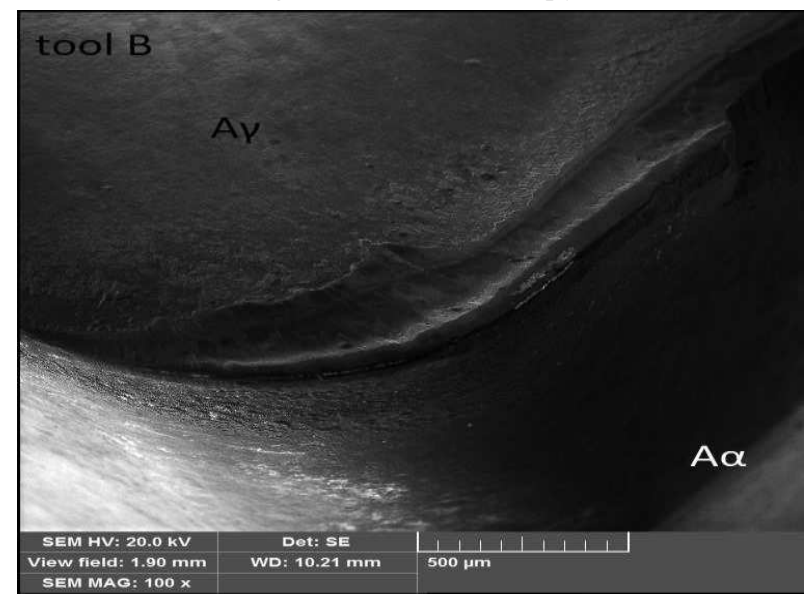

Fig. 15b Flank and face wear of all tested tools B (scanning electron microscopy)

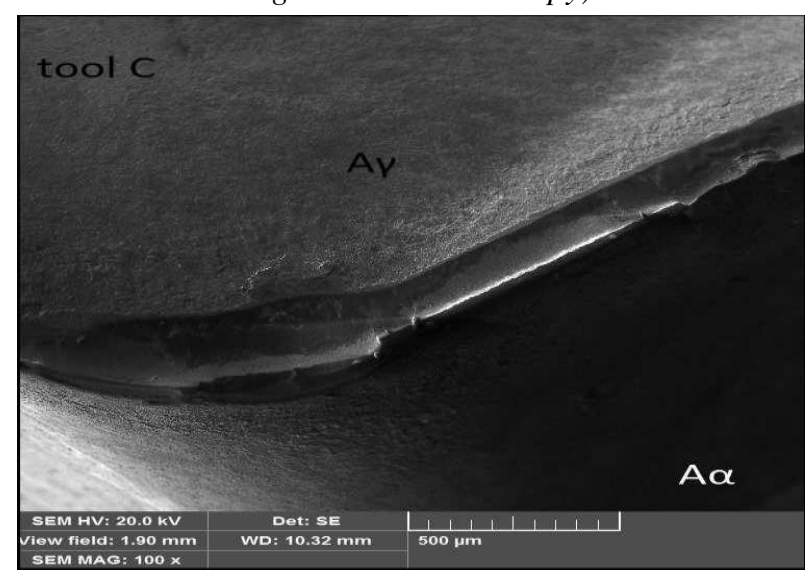

Fig. 15c Flank and face wear of all tested tools C (scanning electron microscopy) 


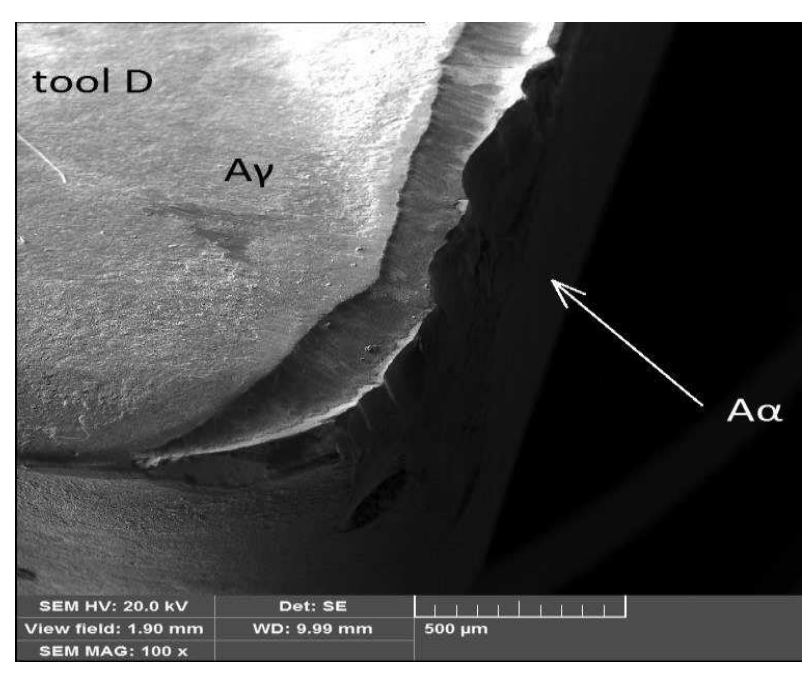

Fig. 15d Flank and face wear of all tested tools D (scanning electron microscopy)

\section{Acknowledgement}

This research work was supported by the BUT, Faculty of Mechanical Engineering, Brno, Specific research 2016, with the grant "Research of modern production technologies for specific applications", FSI-S-16-3717. This work was also supported by the Slovak Research and Development Agency under the contract No. APVV-15-0710.

\section{References}

[1] HUMÁR, A. (2008) Materiály pro řezné nástroje, MM publishing, 235s. ISBN 978-80-254-2250-2.

[2] KOVALEV, A. I. et al Studying the structure of films generated on HSS-based deformed powder materials cutting tool surface. Wear, ISSN 00431648. DOI: 10.1016/S0043-1648(99)003014.

[3] FIALA, Z. et al (2015) Effect of Spindle Unit Extrusion on Stability of Machining Process, In: Manufacturing Technology, Vol. 15, No. 3, s. 329333. ISSN: 1213- 2489.

[4] MATTOX, D. (2010) Handbook of physical vapor deposition (PVD) processing: principles, technology, and applications. 2nd ed. Amsterdam: Elsevier, xlvi, 746 s. ISBN 978-0-81-552037-5.

[5] XU, J. et al. Dynamic Analysis for High-speed Cutters of Five-axis CNC Milling Machine. In:
Manufacturing Technology, Vol. 14, pp. 643-650. ISSN 1213-2489.

[6] PIERSON, H. (1999) Handbook of Chemical vapor deposition (CVD): principles, technology, and applications. 2nd ed. Norwich: Noyes Publications, xxiv., 482 s. ISBN 08-155-1432-8.

[7] CHANG, Y. et al. (2005) Structural and mechanical properties of nanolayered TiAlN/CrN coatings synthesized by a cathodic arc deposition process, In: Surface and Coatings Technology. 2005, 5-6, s. 1702-1708. ISSN 02578972. DOI: 10.1016/j.surfcoat.2005.08.088.

[8] CSELLE, T. et al. (2008) Computer simulations of the growth of PVD coatings and a new series of three-layer coatings. In: MM Prumyslove spektrum.. Available at: http://www.mmspektrum.com/ clanek/pocitacova-simulace-rustu-pvdpovlaku-a-nova-rada-trojvrstvychpovlaku.

[9] JAROŠ, A. et al. (2012) Investigation of the influence of AlTiCrN coating for dry milling of construction steel 1.8159. MMK 2012. 1. Hradec Kralove: Magnanimitas, pp. 3475-3482. ISBN: 978-80-905243-3- 0.

[10] Used milling cutter (2016) catalog. DORMER PRAMET. [Online]. [cit.2016-05-15]. Avalaible at: http://www.dormerpramet.com/downloads/cata-

logue $\% 20$ pramet $\% 202016 \% 20$ czen $\% 20$ bookmarks.pdf.

[11] JAROŠ, A. et al. (2016) Investigation of the influence of PVD coatings deposited on HSS milling cutter, In: Manufacturing Technology, Vol. No. 3, s. 506-512. ISSN: 1213-2489.

[12] JAŠEK, P (2016) The influence of PVD coating on tool life of cutting inserts during face milling. Brno: Brno University of Technology, 73. pp. Diploma thesis.

[13] POKORNÝ, Z., HRUBÝ, V., STUDENÝ, Z.(2016) Effect of nitrogen on surface morphology of layers. In: Kovové Materiály, Vol. 54, No. 2, p. 119-124.

[14] MAJERÍK, J., BARÉNYI, I. (2016) Experimental investigation into tool wear of cemented carbide cutting inserts when machining wear resistant steel Hardox 500. In: Engineering Review, Vol. 36, No. 2, p. 167-174. 